Article

\title{
Combining a Fusion Inhibitory Peptide Targeting the MERS-CoV S2 Protein HR1 Domain and a Neutralizing Antibody Specific for the S1 Protein Receptor-Binding Domain (RBD) Showed Potent Synergism against Pseudotyped MERS-CoV with or without Mutations in RBD
}

\author{
Cong Wang ${ }^{1, \dagger}$, Chen Hua ${ }^{1,+}$, Shuai Xia ${ }^{1}$, Weihua $\mathrm{Li}^{2}$, Lu Lu ${ }^{1, *}$ and Shibo Jiang ${ }^{1,2, *}$ \\ 1 Key Laboratory of Medical Molecular Virology of MOE/MOH, School of Basic Medical Sciences and \\ Shanghai Public Health Clinical Center, Fudan University, Shanghai 200032, China; \\ 16111010068@fudan.edu.cn (C.W.); 16211010047@fudan.edu.cn (C.H.); 15111010053@fudan.edu.cn (S.X.) \\ 2 NHC Key Laboratory of Reproduction Regulation (Shanghai Institute of Planned Parenthood Research), \\ Fudan University, Shanghai 200032, China; weihua.li@sippr.org.cn \\ * Correspondence: lul@fudan.edu.cn (L.L.); shibojiang@fudan.edu.cn (S.J.); Tel.: +86-21-5423-7673 (L.L.); \\ $+86-21-5423-7673$ (S.J.) \\ + These authors contributed equally to this work.
}

Received: 9 December 2018; Accepted: 2 January 2019; Published: 6 January 2019

\begin{abstract}
Middle East respiratory syndrome coronavirus (MERS-CoV) has continuously posed a threat to public health worldwide, yet no therapeutics or vaccines are currently available to prevent or treat MERS-CoV infection. We previously identified a fusion inhibitory peptide (HR2P-M2) targeting the MERS-CoV S2 protein HR1 domain and a highly potent neutralizing monoclonal antibody (m336) specific to the S1 spike protein receptor-binding domain (RBD). However, m336 was found to have reduced efficacy against MERS-CoV strains with mutations in RBD, and HR2P-M2 showed low potency, thus limiting the clinical application of each when administered separately. However, we herein report that the combination of 3336 and HR2P-M2 exhibited potent synergism in inhibiting MERS-CoV S protein-mediated cell-cell fusion and infection by MERS-CoV pseudoviruses with or without mutations in the RBD, resulting in the enhancement of antiviral activity in contrast to either one administered alone. Thus, this combinatorial strategy could be used in clinics for the urgent treatment of MERS-CoV-infected patients.
\end{abstract}

Keywords: MERS-CoV; RBD; mutation; peptide; neutralizing antibody; combination

\section{Introduction}

Middle East respiratory syndrome (MERS) coronavirus (MERS-CoV), a lineage C beta-coronavirus, was reported to cause severe respiratory tract infection [1,2]. To date, 2266 laboratory-confirmed cases of infection with MERS-CoV, including 804 MERS-CoV associated deaths, have been reported to the World Health Organization (WHO) from 27 countries. Currently, no effective therapeutics or vaccines are available to treat or prevent MERS-CoV infection.

The spike (S) protein of MERS-CoV plays important roles in virus attachment, fusion, and entry into the target cell [3-5]. Similar to other coronaviruses, the $S$ protein of MERS-CoV consists of S1 and $\mathrm{S} 2$ subunits. The $\mathrm{S} 1$ subunit is responsible for the binding of the virion by its receptor binding domain (RBD) to the cellular receptor, dipeptidyl peptidase-4 (DPP4), while the S2 subunit mediates the fusion 
between viral and cellular membranes through the interaction between its HR1 and HR2 domains and entry of the viral genetic materials into the host cell [5-8]. Thus, both the RBD in S1 subunit and HR1 domain in S2 subunit can serve as important targets for development of antiviral agents against MERS-CoV infection.

Recently, we identified a peptide derived from the HR2 domain of MERS-CoV S protein S2 subunit, designated HR2P, which could interact with the HR1 domain of S protein S2 subunit to form a six-helix bundle (6-HB) complex and block viral fusion and replication with $\mathrm{IC}_{50}$ s ranging from 0.6 to $1 \mu \mathrm{M}$ [5]. By replacing amino acid residues at the $i$ to $i+4$ positions with a negatively charged amino acid (e.g., E) and a positively charged amino acid (e.g., K) in HR2P for introduction of intramolecular salt-bridges, the resultant peptide HR2P-M2 exhibited improved solubility, stability, and anti-MERS-CoV activity $[5,9]$. However, its potency is still not strong enough to warrant clinical development.

By screening an extra-large phage-displayed antibody Fab library, Ying et al. identified a human neutralizing monoclonal antibody $(\mathrm{hmAb}), \mathrm{m} 336$, which is specific for the RBD in the S protein S1 subunit. It exhibited highly potent neutralizing activity against MERS-CoV infection, both in vitro and in vivo [10-13]. X-ray crystallography has shown that the binding epitope of m336 on MERS-CoV S protein almost completely overlaps with the binding site of DPP4 [14]. However, the future clinical application of m336 could be limited by its inability to neutralize MERS-CoV strains with mutations in RBD, like the mouse neutralizing mAb Mersmab1 with similar weakness [15,16].

In this study, we compared the sensitivity of a pseudotyped MERS-CoV wild-type strain with that of strains with key mutations, including D509G, D510G, Q522H, and I529T, which were detected in the RBD of some MERS-CoV strains isolated from different regions and at different times throughout the course of the MERS outbreak from 2012 to 2015 [17,18]. We found that these strains with mutations in RBD were significantly less sensitive than the wild-type strain to the neutralizing activity of m336, while the pseudoviruses with or without mutations showed equal sensitivity to the fusion inhibitory activity of HR2P-M2. Interestingly, when m336 was combined with HR2P-M2, a strong synergism emerged against MERS-CoV S-mediated cell-cell fusion and infection by pseudotyped MERS-CoV strains with or without mutations in RBD, suggesting that this combinational therapy could be further developed for clinical use to treat patients infected by the MERS-CoV strains with or without mutations in RBD.

\section{Materials and Methods}

\subsection{Cells, Peptides, Human $m A b$ m336, and Plasmids}

The 293T cell line was obtained from ATCC (Manassas, VA, USA), and the Huh-7 cell line was from the Cell Bank of the Chinese Academy of Sciences (Shanghai, China). These two cell lines were propagated in Dulbecco's Modified Eagle's Medium (DMEM) supplemented with 10\% fetal bovine serum (FBS). Peptide HR2P-M2 was synthesized by solid phase peptide synthesis at SYN Inc. (Shanghai, China), and human mAb m336 was provided by Prof. Tianlei Ying at Fudan University, Shanghai, China. Recombinant plasmids encoding the MERS-CoV S protein with D509G, D510G, Q522H, or I529T mutations were kindly provided by Dr. Lanying Du at the New York Blood Center, NY, USA.

\subsection{Production of Pseudoviruses}

MERS-CoV pseudoviruses were constructed as described previously $[19,20]$. Briefly, 293T cells were plated in a T175 tissue culture flask and incubated at $37^{\circ} \mathrm{C}$ for $16 \mathrm{~h}$. Cells were cotransfected with plasmids pNL4-3.luc.RE encoding Env-defective, luciferase-expressing HIV-1 and pcDNA3.1-MERS-CoV-S encoding $S$ protein with or without mutation in RBD at mass ratio of 1:1 using VigoFect (Vigorous Biotechnology, Beijing, China), according to the manufacturer's recommendation. The supernatant was replaced with fresh DMEM at $8-10 \mathrm{~h}$ post-transfection and harvested after incubation for an additional $72 \mathrm{~h}$. In order to remove cell debris, the supernatant was centrifuged at 
$3000 \mathrm{rpm}$ for $10 \mathrm{~min}$, followed by filtration through a $0.45 \mu \mathrm{m}$ filter. MERS-CoV pseudovirus in the supernatant was quantified by testing p24 content in the product of MERS-CoV pseudovirus.

\subsection{Inhibition of Pseudotyped MERS-CoV Infection}

A MERS-CoV pseudovirus inhibition assay was performed as previously described $[5,15,21]$. Briefly, Huh-7 cells were seeded $\left(10^{4}\right.$ cells/well) into a 96-well plate and incubated overnight at $37^{\circ} \mathrm{C}$. MERS-CoV pseudovirus was incubated with a serially diluted inhibitor for $30 \mathrm{~min}$ at $37^{\circ} \mathrm{C}$, followed by the addition of Huh-7 cells. The cells were incubated with or without pseudovirus as virus control and cell control, respectively. The culture was replaced with fresh medium $12 \mathrm{~h}$ post-infection and incubated for an additional $72 \mathrm{~h}$. Cells were lysed using lysis reagent (Promega, Madison, WI, USA), and cell lysates were transferred to a 96-well Costar flat-bottom luminometer plate (Corning Costar, New York, NY, USA), followed by the addition of luciferase substrate (Promega) to measure luminescence using an Infinite M200 PRO (Tecan, GröDig, Austria).

\subsection{Inhibition of MERS-CoV S Protein-Mediated Cell-Cell Fusion}

MERS-CoV S protein-mediated cell-cell fusion was performed as previously described [5]. Briefly, plasmid pAAV-IRES-MERS-EGFP encoding the MERS-CoV S protein was transfected into 293T cells (293T/MERS/EGFP) using the transfection reagent, VigoFect (Vigorous Biotechnology, Beijing, China). The target Huh-7 cells expressing DPP4were incubated at $2 \times 10^{4}$ cells/well in wells of a 96-well plate for $12 \mathrm{~h}$. The effector 293T/MERS/EGFP cells that express MERS-CoV S protein and EGFP or the control 293T/EGFP cells that express EGFP only were preincubated at $10^{4}$ cells/well with an inhibitor at the indicated concentration or phosphate buffered saline (PBS) as control at $37^{\circ} \mathrm{C}$ for $30 \mathrm{~min}$. The mixture of 293T/MERS/EGFP cells and an inhibitor or PBS were added to Huh-7 cells in the wells, followed by a co-culture at $37^{\circ} \mathrm{C}$ for $2 \mathrm{~h}$. The 293T/MERS/EGFP cells fused or unfused with Huh-7 cells were fixed with $4 \%$ PFA and counted under an inverted fluorescence microscope (Nikon, Tokyo, Japan). The fused cell showed much larger size and weaker fluorescence intensity than the unfused cell because of the diffusion of EGFP from one cell to more cells (Figure 1). Almost no fused cells could be observed in the groups of negative control (PBS+293T/EGFP+Huh-7) or peptide treatment (HR2P-M2+293T/MERS/EGFP+Huh-7) (Figure 1). The concentration for $50 \%$ inhibition $\left(\mathrm{IC}_{50}\right)$ was calculated using CalcuSyn software kindly provided by Dr. T.C. Chou [22].

$\mathrm{PBS}+293 \mathrm{~T} / \mathrm{EGFP}+\mathrm{Huh}-7$

PBS + 293T/MERS//EGFP + Huh-7

HR2P-M2 + 293T/MERS/EGFP + Huh-7

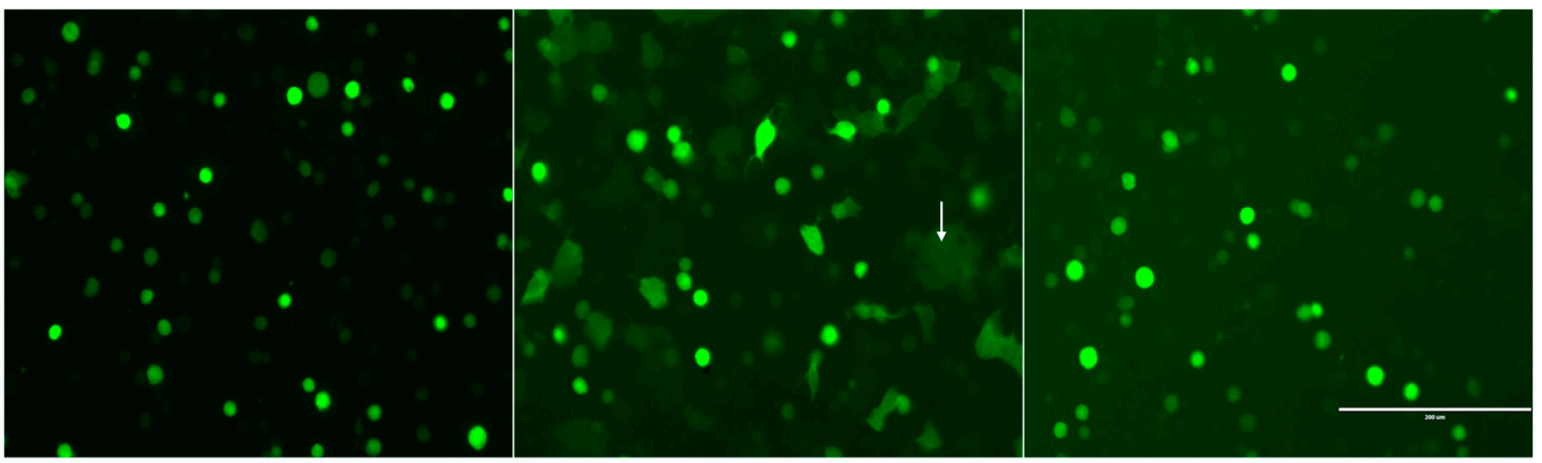

Figure 1. Images of Middle East respiratory syndrome coronavirus (MERS-CoV) S protein-mediated cell-cell fusion. Huh-7 cells were co-cultured with 293T/EGFP cells (left) or 293T/MERS/EGFP cells in the presence of PBS (middle) or $10 \mu \mathrm{M}$ HR2P-M2 peptide (right) at $37^{\circ} \mathrm{C}$ for $2 \mathrm{~h}$. The fused cells (one of the fused cell is indicated by an arrow) and the unfused cells were counted under a fluorescence microscope. Scale bars, $200 \mu \mathrm{m}$.

\subsection{Inhibitory Activity of Sera from Mice Treated with m336 Alone, HR2P-M2 Alone, or m336/HR2P-M2 Combined}

The animal experiment was performed under ethical guidelines for the care and use of laboratory animals of Fudan University, and the protocol was approved by the Institutional Laboratory Animal 
Care and Use Committee at Fudan University (approval number 20160927-1, 27 September 2016). Six-week-old female specific-pathogen-free (SPF) BALB/c mice (bodyweight about $20 \mathrm{~g}$ ) were divided into 3 groups of 3 mice each. Mice in group 1, 2, and 3 were intraperitoneally (i.p.) injected with m336 (0.01 mg in $100 \mu \mathrm{L}$ PBS) alone, HR2P-M2 (1 mg in $100 \mu \mathrm{L}$ PBS) alone, and the combination of m336 (0.01 mg in $100 \mu \mathrm{L}$ PBS) and HR2P-M2 (1 mg in $100 \mu \mathrm{L}$ PBS), respectively. Mice were sedated with Nembutal (100 mg/kg body weight) before and $2 \mathrm{~h}$ after injection of the inhibitors, respectively, and bled retro-orbitally. The blood was centrifuged at $6000 \mathrm{rpm}$ for $10 \mathrm{~min}$ after standing at room temperature for $3 \mathrm{~h}$. The sera were collected and heat-inactivated at $56{ }^{\circ} \mathrm{C}$ for $30 \mathrm{~min}$. Inhibitory activity of the inhibitors on MERS-CoV pseudovirus was evaluated in serum as described above.

\subsection{Inhibitor Combination Assay}

To assess the potential synergistic effect, HR2P-M2 and m336 were mixed at the indicated molar concentration ratio, while HR2P-M2 alone and m336 alone were included as controls. The mixtures were serially diluted and tested for their inhibitory activity on MERS-CoV pseudovirus infection as described above. Each sample was tested in triplicate, and data were analyzed for synergistic effect by calculating the combination index (CI), using the CalcuSyn program. CI values of $<1$ and $>1$ indicate synergy and antagonism, respectively, and synergy was divided into different strengths, according to $C I$ values, as follows: $<0.1$ indicates very strong synergism; $0.1-0.3$ indicates strong synergism; 0.3-0.7 indicates synergism; $0.7-0.85$ indicates moderate synergism; and $0.85-0.90$ indicates slight synergism [23,24]. Fold of potency enhancement was calculated with the ratio of concentrations of inhibitor testing alone and in combination.

\subsection{Statistical Analysis}

To determine the significance of difference in sensitivity between wild-type and mutant viruses to inhibitors and the inhibitory activity detected in sera from BALB/c mice treated with inhibitors alone or combination, statistical analyses were performed using a two-tailed unpaired Student's $t$-test, using GraphPad Prism, version 5.0. Values with $p<0.05$ and $p<0.01$ were considered statistically significant and very significant, respectively.

\section{Results}

\subsection{Combining HR2P-M2 with m336 Exhibited Strong Synergism against MERS-CoV Pseudovirus Infection}

We first investigated the potential cooperative effects of combining HR2P-M2 with m336 on MERS-CoV pseudovirus infection. In our preliminary study, we found that $\mathrm{IC}_{50}$ values of HR2P-M2 and $\mathrm{m} 336$ for inhibiting MERS-CoV pseudovirus infection were about $600 \mathrm{nM}$ and $0.06 \mathrm{nM}$, respectively. Therefore, we tested the inhibitory activity of HR2P-M2 alone, m336 alone, and HR2P-M2/m336 in combination at a molar concentration ratio of 10,000:1, respectively. As shown in Figure 2 and Table 1, combining HR2P-M2 and m336 resulted in strong synergistic inhibitory activity against MERS-CoV pseudovirus infection with CI values of $0.13-0.20$ for 50-90\% inhibition, including potency enhancement of 12.9- to 18.9-fold for m336 and 8.4- to 12.9-fold for HR2P-M2. This result suggested that the MERS-CoV fusion inhibitory peptide HR2P-M2 and the MERS-CoV neutralizing mAb m336 could be used in combination to enhance anti-MERS-CoV activity. 


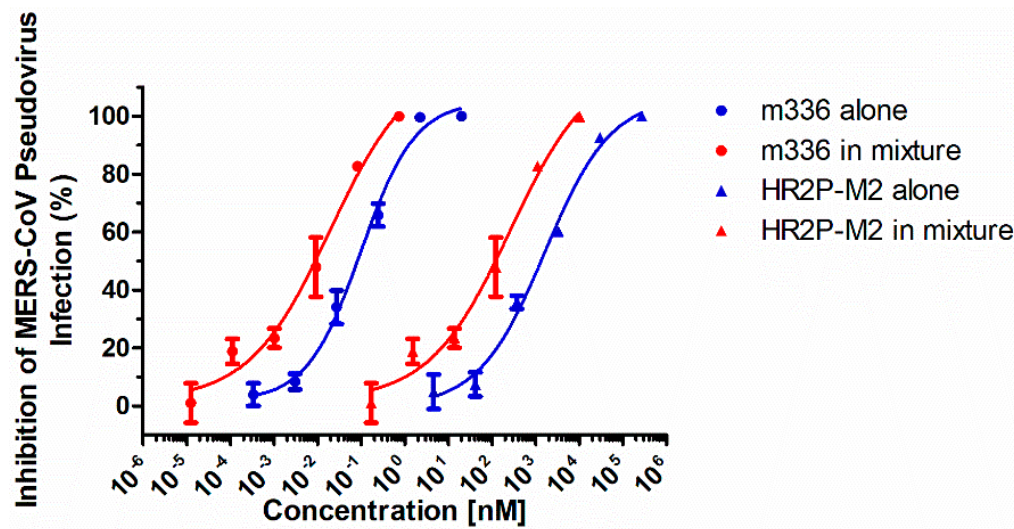

Figure 2. Strong synergism of HR2P-M2 combined with m336 against MERS-CoV pseudovirus infection. The effective concentrations for inhibiting MERS-CoV pseudovirus infection are plotted in two curves. The blue curves represent inhibitors used alone, and the red curves represent each inhibitor used in combination. The width between two curves represents the fold of enhancement between an inhibitor used alone and in combination.

Table 1. Combination index (CI) and fold of enhancement for inhibiting MERS-CoV pseudovirus infection by HR2P-M2 $(\mu \mathrm{M})$ and $\mathrm{m} 336(\mathrm{nM})$ tested in combination.

\begin{tabular}{cccccccc}
\hline & & \multicolumn{3}{c}{ HR2P-M2 } & \multicolumn{3}{c}{ m336 } \\
\cline { 3 - 7 } \% Inhibition & CI & \multicolumn{2}{c}{ Concentration $(\mu \mathbf{M})$} & Fold of & Concentration $(\mathbf{n M})$ & Fold of \\
\cline { 3 - 7 } & & Alone & in Mixture & Enhancement & Alone & in Mixture & Enhancement \\
\hline 50 & 0.197 & 0.574 & 0.069 & 8.36 & 0.066 & 0.005 & 12.94 \\
60 & 0.183 & 0.874 & 0.097 & 9.05 & 0.099 & 0.007 & 13.88 \\
70 & 0.168 & 1.381 & 0.140 & 9.87 & 0.155 & 0.010 & 14.98 \\
80 & 0.152 & 2.415 & 0.220 & 10.96 & 0.268 & 0.016 & 16.44 \\
90 & 0.131 & 5.598 & 0.436 & 12.85 & 0.610 & 0.032 & 18.92 \\
\hline
\end{tabular}

Note: Each sample was tested in triplicate, and the mean values are presented. Ratio of molar concentration of HR2P-M2 and m336 in combination is 10,000:1.

\subsection{Combining HR2P-M2 with m336 Displayed Strong Synergism against MERS-CoV S Protein-Mediated} Cell-Cell Fusion

Next, we tested the potential synergistic activity of the HR2P-M2/m336 combination on MERS-CoV S protein-mediated cell-cell fusion. We adjusted the molar concentration ratio of HR2P-M2 and $\mathrm{m} 336$ in the combination to $4500: 1$, since the IC $_{50}$ values of HR2P-M2 and m336 for inhibiting MERS-CoV S protein-mediated cell-cell fusion in our preliminary studies were about $700 \mathrm{nM}$ and 0.15 $\mathrm{nM}$, respectively. As shown in Figure 3 and Table 2, the combination also exhibited strong synergism against MERS-CoV S protein-mediated cell-cell fusion $(\mathrm{CI}=0.27)$ with enhancement of 18 -fold for m336 and 4-fold for HR2P-M2. This result confirms that combining HR2P-M2, a MERS-CoV fusion inhibitor, with $\mathrm{m} 336$, a human neutralizing $\mathrm{mAb}$, results in strong synergism on $\mathrm{S}$ protein-mediated membrane fusion because they target the different stages of MERS-CoV fusion and entry processes. 


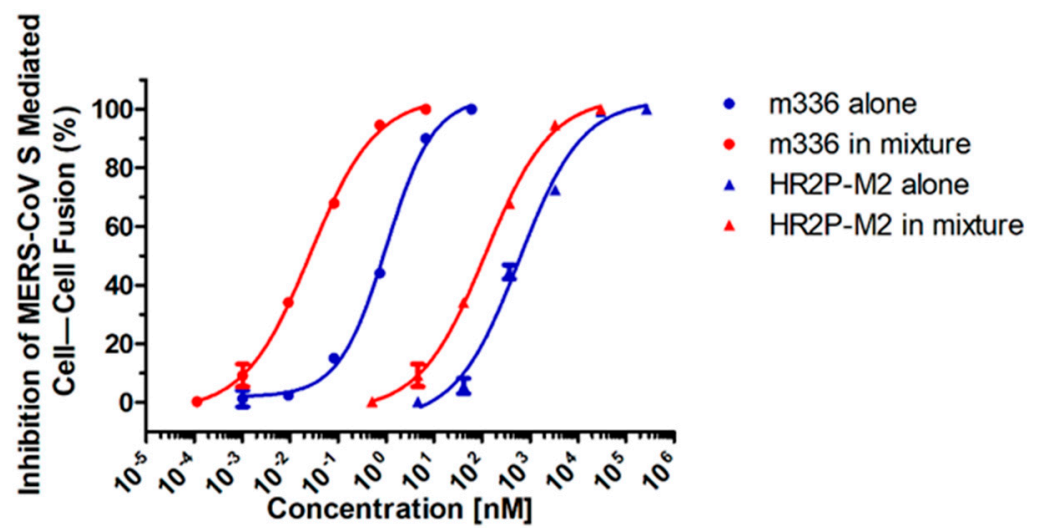

Figure 3. Strong synergism resulting from the HR2P-M2/m336 combination against MERS-CoV S protein-mediated cell-cell fusion.

Table 2. Combination index and fold of enhancement for inhibiting MERS-CoV S protein-mediated cell-cell fusion by the HR2P-M2/m336 combination.

\begin{tabular}{cccccccc}
\hline \multirow{2}{*}{ \% Inhibition } & \multirow{2}{*}{ CI } & \multicolumn{3}{c}{ HR2P-M2 } & \multicolumn{3}{c}{ m336 } \\
\cline { 3 - 7 } & & \multicolumn{2}{c}{ Concentration $(\boldsymbol{\mu M})$} & Fold of & Concentration $(\mathbf{n M})$ & Fold of \\
\cline { 3 - 7 } & Alone & in Mixture & Enhancement & Alone & in Mixture & Enhancement \\
\hline 50 & 0.271 & 0.511 & 0.110 & 4.64 & 0.440 & 0.024 & 17.96 \\
60 & 0.274 & 0.713 & 0.156 & 4.57 & 0.625 & 0.035 & 18.04 \\
70 & 0.278 & 1.025 & 0.228 & 4.50 & 0.918 & 0.051 & 18.12 \\
80 & 0.282 & 1.596 & 0.362 & 4.41 & 1.466 & 0.080 & 18.22 \\
90 & 0.288 & 3.106 & 0.726 & 4.28 & 2.965 & 0.161 & 18.38 \\
\hline
\end{tabular}

Note: Each sample was tested in triplicate, and the mean values are presented. The molar concentration ratio of HR2P-M2 and m336 in combination is 4500:1.

3.3. MERS-CoV Pseudoviruses with Mutations in RBD Mutant of MERS-CoV Were Resistant to RBD-Specific $m A b$ m336, While They Were Equally Sensitive to the HR1-Targeting Peptide HR2P-M2

Du et al. have previously shown that MERS-CoV pseudoviruses with mutations in RBD, such as D509G and D510G detected in some MERS-CoV strains isolated from different regions and at different times $[17,18]$, are resistant to the neutralizing activity of an RBD-specific mouse mAb Mersmab1 [16]. In the present study, the sensitivity of pseudotyped MERS-CoV strains with key mutations in RBD, as identified in some MERS-CoV mutants isolated during the 2012-2015 outbreaks [17], including D509G, D510G, Q522H, and I529T, along with wild-type MERS-CoV, was compared between the inhibitory activity of HR2P-M2 peptide alone and m336 neutralizing mAb alone. As shown in Table 3, the resistance of MERS-CoV mutants to the neutralizing activity of m336 is about 2- to 8-fold, whereas the pseudoviruses with or without mutations were equally sensitive to fusion inhibitory activity of HR2P-M2. This result suggested that use of mAb m336 alone is unable to control the infection by MERS-CoV strains with mutations in RBD. 
Table 3. Sensitivity of MERS-CoV pseudoviruses with or without mutations in the receptor-binding domain (RBD) to the inhibitory activity of m336 (nM) and HR2P-M2 ( $\mu \mathrm{M})$ separately.

\begin{tabular}{ccccccc}
\hline $\begin{array}{c}\text { MERS-CoV } \\
\text { Pseudovirus }\end{array}$ & $\begin{array}{c}\mathbf{I C}_{\mathbf{5 0}}(\mathbf{n M}) \text { of } \\
\mathbf{m 3 3 6}\end{array}$ & $\begin{array}{c}\mathbf{R R}_{\mathbf{5 0}} \text { (Fold of } \\
\text { Resistance) }\end{array}$ & $\boldsymbol{p}$ & $\begin{array}{c}\mathbf{I C}_{\mathbf{5 0}}(\boldsymbol{\mu M}) \text { of } \\
\text { HR2P-M2 }\end{array}$ & $\begin{array}{c}\mathbf{R R}_{\mathbf{5 0}} \text { (Fold of } \\
\text { Resistance) }\end{array}$ & $\boldsymbol{p}$ \\
\hline Wild-type & $0.055 \pm 0.009$ & - & - & $0.553 \pm 0.056$ & - & - \\
D509G & $0.116 \pm 0.020$ & 2.11 & $<0.01$ & $0.619 \pm 0.079$ & 1.12 & $>0.05$ \\
D510G & $0.450 \pm 0.085$ & 8.18 & $<0.05$ & $0.679 \pm 0.144$ & 1.23 & $>0.05$ \\
Q522H & $0.148 \pm 0.051$ & 2.69 & $<0.01$ & $0.677 \pm 0.071$ & 1.22 & $>0.05$ \\
I529T & $0.215 \pm 0.055$ & 3.91 & $<0.01$ & $0.574 \pm 0.209$ & 1.04 & $>0.05$ \\
\hline
\end{tabular}

Note: Each sample was tested in triplicate. Data are presented as means \pm SD. Resistance ratio $\left(R_{50}\right)$ values are based on $\mathrm{IC}_{50}$ of a mutant strain divided by $\mathrm{IC}_{50}$ of the wild-type stain. The significance of the difference between a mutant strain and the wild-type strain was statistically analyzed by a two-tailed unpaired Student's $t$-test using GraphPad Prism, version 5.0. Values with $p<0.05$ and $p<0.01$ were considered statistically significant and very significant, respectively.

3.4. Combining m336 with HR2P-M2 Exhibited Potent Synergism against MERS-CoV Pseudoviruses with or without Mutations in RBD or Those in the HR1 Domain

To determine whether the combination of HR2P-M2 and m336 also exhibited synergistic antiviral activity against infection of MERS-CoV strains with mutations in RBD or in the HR1 domain, we constructed pseudoviruses bearing MERS-CoV S protein with mutations in RBD, including D509G, D510G, Q522H, or I529T, and those in the HR1 domain, including Q1020H and Q1020R [25,26]. We then tested their sensitivity to the inhibition of HR2P-M2 alone, m336 alone, and the HR2P-M2/m336 combination. As shown in Table 4, combining m336 with HR2P-M2 exhibited strong synergism against infection by pseudotyped MERS-CoV strains with or without mutations in the RBD or HR1 domain with $\mathrm{CI}$ value less than 0.3 and potency enhancement in the range of 6- to 25-fold, suggesting that this combinational therapy has potential to be further developed for treatment of patients infected by different MERS-CoV strains, including those with resistance to RBD-specific neutralizing antibodies.

Table 4. Combination index and fold of enhancement for inhibiting MERS-CoV pseudoviruses with or without mutations in RBD in S1 subunit and HR1 in S2 subunit of MERS-CoV S protein by HR2P-M2 and $\mathrm{m} 336$

\begin{tabular}{|c|c|c|c|c|c|c|c|}
\hline \multirow{3}{*}{$\%$ Inhibition } & \multirow{3}{*}{ CI } & \multicolumn{3}{|c|}{ HR2P-M2 } & \multicolumn{3}{|c|}{ m336 } \\
\hline & & \multicolumn{2}{|c|}{ Concentration $(\mu \mathrm{M})$} & \multirow{2}{*}{$\begin{array}{c}\text { Fold of } \\
\text { Enhancement }\end{array}$} & \multicolumn{2}{|c|}{ Concentration $(\mu \mathrm{M})$} & \multirow{2}{*}{$\begin{array}{c}\text { Fold of } \\
\text { Enhancement }\end{array}$} \\
\hline & & Alone & in Mixture & & Alone & in Mixture & \\
\hline \multicolumn{8}{|c|}{ Wild type } \\
\hline 50 & 0.197 & 0.574 & 0.069 & 8.36 & 0.066 & 0.005 & 12.94 \\
\hline 60 & 0.183 & 0.874 & 0.097 & 9.05 & 0.099 & 0.007 & 13.88 \\
\hline 70 & 0.168 & 1.381 & 0.140 & 9.87 & 0.155 & 0.010 & 14.98 \\
\hline 80 & 0.152 & 2.415 & 0.220 & 10.96 & 0.268 & 0.016 & 16.44 \\
\hline 90 & 0.131 & 5.598 & 0.436 & 12.85 & 0.610 & 0.032 & 18.92 \\
\hline \multicolumn{8}{|c|}{ D509G in RBD } \\
\hline 50 & 0.296 & 0.912 & 0.155 & 5.88 & 0.273 & 0.034 & 7.91 \\
\hline 60 & 0.29 & 1.335 & 0.217 & 6.15 & 0.379 & 0.048 & 7.87 \\
\hline 70 & 0.282 & 2.023 & 0.313 & 6.47 & 0.544 & 0.070 & 7.83 \\
\hline 80 & 0.274 & 3.358 & 0.489 & 6.87 & 0.844 & 0.109 & 7.77 \\
\hline 90 & 0.263 & 7.199 & 0.956 & 7.53 & 1.635 & 0.213 & 7.69 \\
\hline \multicolumn{8}{|c|}{ D510G in RBD } \\
\hline 50 & 0.137 & 0.962 & 0.088 & 10.96 & 0.429 & 0.020 & 21.96 \\
\hline 60 & 0.145 & 1.523 & 0.153 & 9.96 & 0.763 & 0.034 & 22.43 \\
\hline 70 & 0.155 & 2.512 & 0.280 & 8.97 & 1.429 & 0.062 & 22.97 \\
\hline 80 & 0.169 & 4.625 & 0.586 & 7.90 & 3.075 & 0.130 & 23.63 \\
\hline 90 & 0.194 & 11.59 & 1.777 & 6.52 & 9.74 & 0.395 & 24.67 \\
\hline
\end{tabular}


Table 4. Cont.

\begin{tabular}{|c|c|c|c|c|c|c|c|}
\hline \multirow{3}{*}{$\%$ Inhibition } & \multirow{3}{*}{ CI } & \multicolumn{3}{|c|}{ HR2P-M2 } & \multicolumn{3}{|c|}{ m336 } \\
\hline & & \multicolumn{2}{|c|}{ Concentration $(\mu \mathrm{M})$} & \multirow{2}{*}{$\begin{array}{c}\text { Fold of } \\
\text { Enhancement }\end{array}$} & \multicolumn{2}{|c|}{ Concentration $(\mu \mathrm{M})$} & \multirow{2}{*}{$\begin{array}{c}\text { Fold of } \\
\text { Enhancement }\end{array}$} \\
\hline & & Alone & in Mixture & & Alone & in Mixture & \\
\hline \multicolumn{8}{|c|}{ Q522H in RBD } \\
\hline 50 & 0.135 & 0.799 & 0.045 & 17.59 & 0.129 & 0.010 & 12.76 \\
\hline 60 & 0.143 & 1.243 & 0.067 & 18.67 & 0.166 & 0.015 & 11.21 \\
\hline 70 & 0.153 & 2.012 & 0.101 & 19.93 & 0.219 & 0.022 & 9.74 \\
\hline 80 & 0.168 & 3.619 & 0.168 & 21.57 & 0.306 & 0.037 & 8.21 \\
\hline 90 & 0.199 & 8.757 & 0.36 & 24.30 & 0.508 & 0.08 & 6.34 \\
\hline \multicolumn{8}{|c|}{ I529T in RBD } \\
\hline 50 & 0.256 & 0.864 & 0.098 & 8.81 & 0.153 & 0.022 & 7.03 \\
\hline 60 & 0.242 & 1.295 & 0.139 & 9.32 & 0.23 & 0.031 & 7.45 \\
\hline 70 & 0.227 & 2.013 & 0.203 & 9.90 & 0.358 & 0.045 & 7.92 \\
\hline 80 & 0.211 & 3.449 & 0.323 & 10.67 & 0.614 & 0.072 & 8.55 \\
\hline 90 & 0.188 & 7.752 & 0.649 & 11.94 & 1.383 & 0.144 & 9.58 \\
\hline \multicolumn{8}{|c|}{ Q1020H in HR1 } \\
\hline 50 & 0.186 & 0.762 & 0.086 & 8.83 & 0.088 & 0.006 & 13.82 \\
\hline 60 & 0.189 & 0.954 & 0.106 & 9.04 & 0.100 & 0.008 & 12.84 \\
\hline 70 & 0.192 & 1.218 & 0.131 & 9.27 & 0.115 & 0.010 & 11.85 \\
\hline 80 & 0.198 & 1.642 & 0.172 & 9.56 & 0.137 & 0.013 & 10.74 \\
\hline 90 & 0.208 & 2.571 & 0.257 & 10.01 & 0.176 & 0.019 & 9.27 \\
\hline \multicolumn{8}{|c|}{ Q1020R in HR1 } \\
\hline 50 & 0.293 & 0.69 & 0.119 & 5.79 & 0.073 & 0.009 & 8.30 \\
\hline 60 & 0.28 & 0.905 & 0.143 & 6.32 & 0.087 & 0.011 & 8.19 \\
\hline 70 & 0.268 & 1.216 & 0.175 & 6.95 & 0.104 & 0.013 & 8.06 \\
\hline 80 & 0.254 & 1.743 & 0.223 & 7.80 & 0.131 & 0.017 & 7.92 \\
\hline 90 & 0.238 & 2.997 & 0.323 & 9.29 & 0.184 & 0.024 & 7.70 \\
\hline
\end{tabular}

Note: The molar concentration ratio of HR2P-M2 and m336 in combination against wildtype virus, viruses with mutations in RBD, and those in HR1 is 10,000:1, 4500:1, and 10,000:1, respectively.

\subsection{Sera from Mice Treated with the m336/HR2P-M2 Combination Showed More Efficacy in Inhibiting} MERS-CoV Pseudovirus Infection than Either HR2P-M2 or m336 Alone

To determine whether the HR2P-M2/m336 combination could sustain its efficacy in vivo compared to HR2P-M2 or m336 alone, we tested the anti-MERS-CoV pseudovirus activity of the inhibitors in sera of mice treated with i.p. injection of HR2P-M2, m336, and the HR2P-M2/m336 combination, respectively. As shown in Figure 4, the inhibitory activity detected in sera from mice treated with HR2P-M2 or m336 alone was significantly higher than that detected in sera from mice before inhibition of any inhibitor. On the other hand, the anti-MERS-CoV activity detected in sera from mice treated with the HR2P-M2/m336 combination was significantly more potent than that detected in sera of mice administered with HR2P-M2 or m336 alone. This result confirms that combining HR2P-M2 with m336 affords synergism against MERS-CoV S infection, both in vitro and in vivo.

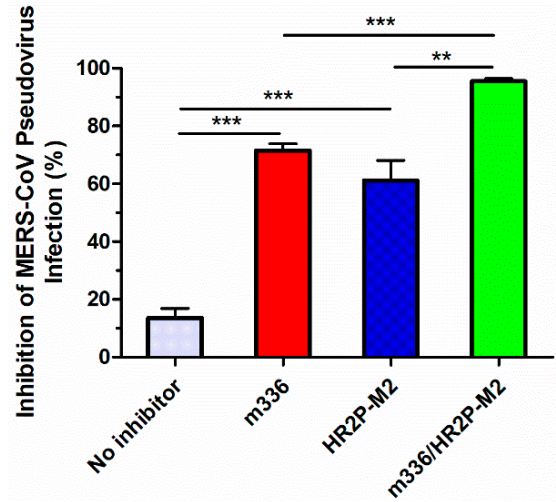

Figure 4. MERS-CoV pseudovirus inhibitory activity as determined from sera of BALB/c mice treated with m336 (0.01 mg) alone, HR2P-M2 (1 mg) alone, or m336 (0.01 mg)/HR2P-M2 (1 mg) in combination. Data are presented as means $\pm \mathrm{SD}$. ${ }^{* *}$, and ${ }^{* * *}$ represent $p<0.01$, and $p<0.001$, respectively. 


\section{Discussion}

The high mortality of MERS-CoV-infected patients [27-29] calls for the development of highly effective anti-MERS-CoV therapeutics. Although we and others have previously identified a MERS-CoV fusion inhibitory peptide (HR2P-M2) targeting the MERS-CoV S2 protein HR1 domain and a highly potent human neutralizing $\mathrm{mAb}$ (m336) targeting the MERS-CoV S1 protein RBD [10,26,30], their further development is limited by low potency in the case of HR2P-M2 and low efficacy to neutralize MERS-CoV strains with RBD mutations in the case of m336 [10,31-33].

The combinatorial use of drugs with different mechanisms of action, i.e., cocktail regimen, has been widely applied in clinics [22]. For example, the combinatorial use of HIV reverse transcriptase (RT) inhibitors and protease inhibitors, known as highly active anti-retrovirus therapy (HAART), has shown significant synergism in inhibiting HIV-1 infection, reducing adverse effects and delaying the emergence of drug resistance, thus extending the lifespan of millions of HIV/AIDS patients [34-36]. Moreover, we previously showed that combining HIV-1 attachment inhibitors with RT inhibitors, or combining the 1st, 2nd, and/or 3rd generation HIV fusion inhibitors that target different sites in the HIV-1 gp41 HR1 domain, exhibited synergistic and complementary effect against infection by a broad spectrum of HIV-1 strains, including those resistant to HIV attachment inhibitors, fusion inhibitors, and RT inhibitors [37-39].

In this study, we compared the anti-MERS-CoV activity of HR2P-M2 alone and m336 alone with that of HR2P-M2/m336 in combination and found that the inhibitory activity of the HR2P-M2/m336 combination was significantly more potent than either one administered alone against MERS-CoV $\mathrm{S}$ protein-mediated cell-cell fusion and MERS-CoV pseudovirus infection, suggesting synergistic activity based on the dual mechanisms of action whereby HR2P-M2 targets the S2 subunit HR1 domain for inhibiting S2-mediated virus-cell or cell-cell fusion [5] and m336 targets the S1 subunit RBD for inhibiting virus-cell binding or virus attachment [10]. It has been well known that drug synergism can be expected when drugs that act by different mechanisms of action are mixed together [22]. While MERS-CoV pseudoviruses with mutations in RBD were resistant to the RBD-specific $\mathrm{mAb}$ m336, they were equally sensitive to HR1-targeting peptide HR2P-M2. Notably, however, the HR2P-M2/m336 combination exhibited strong synergistic antiviral activity against all pseudotyped MERS-CoV strains, including those with mutations in RBD of S protein, which are even resistant to an RBD-specific mouse mAb Mersmab1 [16]. We also demonstrated that sera from mice treated with the HR2P-M2/m336 combination revealed significant efficacy in inhibiting MERS-CoV pseudovirus infection compared to HR2P-M2 or m336 alone. Collectively, these results suggest that the combinatorial strategy overcomes the weaknesses of HR2P-M2 peptide and $\mathrm{m} 336 \mathrm{mAb}$, while, at the same time, takes advantage of the unique mechanism of action of each to provide, by the sum of both, much more effective inhibitory activity against MERS-CoV infection than either peptide or $\mathrm{mAb}$ used alone. The strong synergy of the combination is expected to reduce the dosage of the individual inhibitor in such combinational therapy, resulting in decreased cost and toxicity, thus making the final product more affordable and safer. Therefore, this combinational therapy shows promise for further clinical development.

Author Contributions: S.J. and L.L. conceived and designed the experiments; C.W. and C.H. performed the experiments; C.W., C.H., S.X., W.L. and S.J. analyzed the data; C.W., W.L., L.L. and S.J. wrote the paper. All authors discussed the results and contributed to the final manuscript.

Funding: This work was supported by the National Natural Science Foundation of China (81630090 to Shibo Jiang; 81672019 and 8161101485 to Lu Lu), the National Key Research and Development Program of China (2016YFC1201000 and 2016YFC1200405 to Shibo Jiang, 2016YFC1202901 to Lu Lu), and the National Megaprojects of China for Major Infectious Diseases (2018ZX10301403 to Lu Lu).

Acknowledgments: We thank Lanying Du at the New York Blood Center for providing the plasmid encoding MERS-CoV S protein with mutation in RBD and Tianlei Ying at Fudan University for providing mAb m336.

Conflicts of Interest: The authors declare no competing financial interests. 


\section{References}

1. Zaki, A.M.; van Boheemen, S.; Bestebroer, T.M.; Osterhaus, A.D.; Fouchier, R.A. Isolation of a novel coronavirus from a man with pneumonia in Saudi Arabia. N. Engl. J. Med. 2012, 367, 1814-1820. [CrossRef] [PubMed]

2. de Groot, R.J.; Baker, S.C.; Baric, R.S.; Brown, C.S.; Drosten, C.; Enjuanes, L.; Fouchier, R.A.; Galiano, M.; Gorbalenya, A.E.; Memish, Z.A.; et al. Middle East respiratory syndrome coronavirus (MERS-CoV): Announcement of the Coronavirus Study Group. J. Virol. 2013, 87, 7790-7792. [CrossRef] [PubMed]

3. Belouzard, S.; Millet, J.K.; Licitra, B.N.; Whittaker, G.R. Mechanisms of coronavirus cell entry mediated by the viral spike protein. Viruses 2012, 4, 1011-1033. [CrossRef] [PubMed]

4. Wang, N.; Shi, X.; Jiang, L.; Zhang, S.; Wang, D.; Tong, P.; Guo, D.; Fu, L.; Cui, Y.; Liu, X.; et al. Structure of MERS-CoV spike receptor-binding domain complexed with human receptor DPP4. Cell Res. 2013, 23, 986-993. [CrossRef] [PubMed]

5. Lu, L.; Liu, Q.; Zhu, Y.; Chan, K.H.; Qin, L.; Li, Y.; Wang, Q.; Chan, J.F.; Du, L.; Yu, F.; et al. Structure-based discovery of Middle East respiratory syndrome coronavirus fusion inhibitor. Nat. Commun. 2014, 5, 3067. [CrossRef] [PubMed]

6. Du, L.; Zhao, G.; Kou, Z.; Ma, C.; Sun, S.; Poon, V.K.; Lu, L.; Wang, L.; Debnath, A.K.; Zheng, B.J.; et al. Identification of a receptor-binding domain in the $S$ protein of the novel human coronavirus Middle East respiratory syndrome coronavirus as an essential target for vaccine development. J. Virol. 2013, 87, 9939-9942. [CrossRef]

7. Raj, V.S.; Mou, H.; Smits, S.L.; Dekkers, D.H.; Muller, M.A.; Dijkman, R.; Muth, D.; Demmers, J.A.; Zaki, A.; Fouchier, R.A.; et al. Dipeptidyl peptidase 4 is a functional receptor for the emerging human coronavirus-EMC. Nature 2013, 495, 251-254. [CrossRef]

8. Gao, J.; Lu, G.; Qi, J.; Li, Y.; Wu, Y.; Deng, Y.; Geng, H.; Li, H.; Wang, Q.; Xiao, H.; et al. Structure of the fusion core and inhibition of fusion by a heptad repeat peptide derived from the $\mathrm{S}$ protein of Middle East respiratory syndrome coronavirus. J. Virol. 2013, 87, 13134-13140. [CrossRef]

9. Tao, X.; Garron, T.; Agrawal, A.S.; Algaissi, A.; Peng, B.H.; Wakamiya, M.; Chan, T.S.; Lu, L.; Du, L.; Jiang, S.; et al. Characterization and Demonstration of the Value of a Lethal Mouse Model of Middle East Respiratory Syndrome Coronavirus Infection and Disease. J. Virol. 2016, 90, 57-67. [CrossRef]

10. Ying, T.; Du, L.; Ju, T.W.; Prabakaran, P.; Lau, C.C.; Lu, L.; Liu, Q.; Wang, L.; Feng, Y.; Wang, Y.; et al. Exceptionally potent neutralization of Middle East respiratory syndrome coronavirus by human monoclonal antibodies. J. Virol. 2014, 88, 7796-7805. [CrossRef]

11. Houser, K.V.; Gretebeck, L.; Ying, T.; Wang, Y.; Vogel, L.; Lamirande, E.W.; Bock, K.W.; Moore, I.N.; Dimitrov, D.S.; Subbarao, K. Prophylaxis With a Middle East Respiratory Syndrome Coronavirus (MERS-CoV)-Specific Human Monoclonal Antibody Protects Rabbits From MERS-CoV Infection. J. Infect. Dis. 2016, 213, 1557-1561. [CrossRef] [PubMed]

12. Agrawal, A.S.; Ying, T.; Tao, X.; Garron, T.; Algaissi, A.; Wang, Y.; Wang, L.; Peng, B.H.; Jiang, S.; Dimitrov, D.S.; et al. Passive Transfer of A Germline-like Neutralizing Human Monoclonal Antibody Protects Transgenic Mice Against Lethal Middle East Respiratory Syndrome Coronavirus Infection. Sci. Rep. 2016, 6, 31629. [CrossRef] [PubMed]

13. van Doremalen, N.; Falzarano, D.; Ying, T.; de Wit, E.; Bushmaker, T.; Feldmann, F.; Okumura, A.; Wang, Y.; Scott, D.P.; Hanley, P.W.; et al. Efficacy of antibody-based therapies against Middle East respiratory syndrome coronavirus (MERS-CoV) in common marmosets. Antiviral Res. 2017, 143, 30-37. [CrossRef] [PubMed]

14. Ying, T.; Prabakaran, P.; Du, L.; Shi, W.; Feng, Y.; Wang, Y.; Wang, L.; Li, W.; Jiang, S.; Dimitrov, D.S.; et al. Junctional and allele-specific residues are critical for MERS-CoV neutralization by an exceptionally potent germline-like antibody. Nat. Commun. 2015, 6, 8223. [CrossRef] [PubMed]

15. Du, L.; Zhao, G.; Yang, Y.; Qiu, H.; Wang, L.; Kou, Z.; Tao, X.; Yu, H.; Sun, S.; Tseng, C.T.; et al. A conformation-dependent neutralizing monoclonal antibody specifically targeting receptor-binding domain in Middle East respiratory syndrome coronavirus spike protein. J. Virol. 2014, 88, 7045-7053. [CrossRef] [PubMed] 
16. Tai, W.; Wang, Y.; Fett, C.A.; Zhao, G.; Li, F.; Perlman, S.; Jiang, S.; Zhou, Y.; Du, L. Recombinant Receptor-Binding Domains of Multiple Middle East Respiratory Syndrome Coronaviruses (MERS-CoVs) Induce Cross-Neutralizing Antibodies against Divergent Human and Camel MERS-CoVs and Antibody Escape Mutants. J. Virol. 2017, 91. [CrossRef] [PubMed]

17. Kim, Y.; Cheon, S.; Min, C.K.; Sohn, K.M.; Kang, Y.J.; Cha, Y.J.; Kang, J.I.; Han, S.K.; Ha, N.Y.; Kim, G.; et al. Spread of Mutant Middle East Respiratory Syndrome Coronavirus with Reduced Affinity to Human CD26 during the South Korean Outbreak. mBio 2016, 7, e00019. [CrossRef]

18. Kim, D.W.; Kim, Y.J.; Park, S.H.; Yun, M.R.; Yang, J.S.; Kang, H.J.; Han, Y.W.; Lee, H.S.; Kim, H.M.; Kim, H.; et al. Variations in Spike Glycoprotein Gene of MERS-CoV, South Korea, 2015. Emerg. Infect. Dis. 2016, 22, 100-104. [CrossRef]

19. Zhao, G.; Du, L.; Ma, C.; Li, Y.; Li, L.; Poon, V.K.; Wang, L.; Yu, F.; Zheng, B.J.; Jiang, S.; et al. A safe and convenient pseudovirus-based inhibition assay to detect neutralizing antibodies and screen for viral entry inhibitors against the novel human coronavirus MERS-CoV. Virol. J. 2013, 10, 266. [CrossRef]

20. Gunaratne, G.S.; Yang, Y.; Li, F.; Walseth, T.F.; Marchant, J.S. NAADP-dependent Ca(2+) signaling regulates Middle East respiratory syndrome-coronavirus pseudovirus translocation through the endolysosomal system. Cell Calcium 2018, 75, 30-41. [CrossRef]

21. Wang, L.; Shi, W.; Chappell, J.D.; Joyce, M.G.; Zhang, Y.; Kanekiyo, M.; Becker, M.M.; van Doremalen, N.; Fischer, R.; Wang, N.; et al. Importance of neutralizing monoclonal antibodies targeting multiple antigenic sites on MERS-CoV Spike to avoid neutralization escape. J. Virol. 2018. [CrossRef]

22. Chou, T.C. Theoretical basis, experimental design, and computerized simulation of synergism and antagonism in drug combination studies. Pharmacol. Rev. 2006, 58, 621-681. [CrossRef] [PubMed]

23. Qi, Q.; Wang, Q.; Chen, W.; Yu, F.; Du, L.; Dimitrov, D.S.; Lu, L.; Jiang, S. Anti-HIV antibody and drug combinations exhibit synergistic activity against drug-resistant HIV-1 strains. J. Infect. 2017, 75, 68-71. [CrossRef] [PubMed]

24. Xu, W.; Wang, Q.; Yu, F.; Lu, L.; Jiang, S. Synergistic effect resulting from combinations of a bifunctional HIV-1 antagonist with antiretroviral drugs. J. Acquir. Immune Defic. Syndr. 2014, 67, 1-6. [CrossRef] [PubMed]

25. Cotten, M.; Watson, S.J.; Zumla, A.I.; Makhdoom, H.Q.; Palser, A.L.; Ong, S.H.; Al Rabeeah, A.A.; Alhakeem, R.F.; Assiri, A.; Al-Tawfiq, J.A.; et al. Spread, circulation, and evolution of the Middle East respiratory syndrome coronavirus. mBio 2014, 5. [CrossRef] [PubMed]

26. Channappanavar, R.; Lu, L.; Xia, S.; Du, L.; Meyerholz, D.K.; Perlman, S.; Jiang, S. Protective Effect of Intranasal Regimens Containing Peptidic Middle East Respiratory Syndrome Coronavirus Fusion Inhibitor Against MERS-CoV Infection. J. Infect. Dis. 2015, 212, 1894-1903. [CrossRef] [PubMed]

27. Zumla, A.; Hui, D.S.; Perlman, S. Middle East respiratory syndrome. Lancet 2015, 386, 995-1007. [CrossRef]

28. van Boheemen, S.; de Graaf, M.; Lauber, C.; Bestebroer, T.M.; Raj, V.S.; Zaki, A.M.; Osterhaus, A.D.; Haagmans, B.L.; Gorbalenya, A.E.; Snijder, E.J.; et al. Genomic characterization of a newly discovered coronavirus associated with acute respiratory distress syndrome in humans. mBio 2012, 3. [CrossRef]

29. Assiri, A.; McGeer, A.; Perl, T.M.; Price, C.S.; Al Rabeeah, A.A.; Cummings, D.A.; Alabdullatif, Z.N.; Assad, M.; Almulhim, A.; Makhdoom, H.; et al. Hospital outbreak of Middle East respiratory syndrome coronavirus. N. Engl. J. Med. 2013, 369, 407-416. [CrossRef]

30. Lu, L.; Xia, S.; Ying, T.; Jiang, S. Urgent development of effective therapeutic and prophylactic agents to control the emerging threat of Middle East respiratory syndrome (MERS). Emerg. Microbes Infect. 2015, 4, e37. [CrossRef]

31. Xia, S.; Liu, Q.; Wang, Q.; Sun, Z.; Su, S.; Du, L.; Ying, T.; Lu, L.; Jiang, S. Middle East respiratory syndrome coronavirus (MERS-CoV) entry inhibitors targeting spike protein. Virus Res. 2014, 194, 200-210. [CrossRef] [PubMed]

32. Zhao, G.; He, L.; Sun, S.; Qiu, H.; Tai, W.; Chen, J.; Li, J.; Chen, Y.; Guo, Y.; Wang, Y.; et al. A Novel Nanobody Targeting Middle East Respiratory Syndrome Coronavirus (MERS-CoV) Receptor-Binding Domain Has Potent Cross-Neutralizing Activity and Protective Efficacy against MERS-CoV. J. Virol. 2018, 92. [CrossRef] [PubMed]

33. Kleine-Weber, H.; Elzayat, M.T.; Wang, L.; Graham, B.S.; Muller, M.A.; Drosten, C.; Pohlmann, S.; Hoffmann, M. Mutations in the spike protein of MERS-CoV transmitted in Korea increase resistance towards antibody-mediated neutralization. J. Virol. 2018. [CrossRef] [PubMed] 
34. Zhang, L.; Ramratnam, B.; Tenner-Racz, K.; He, Y.; Vesanen, M.; Lewin, S.; Talal, A.; Racz, P.; Perelson, A.S.; Korber, B.T.; et al. Quantifying residual HIV-1 replication in patients receiving combination antiretroviral therapy. N. Engl. J. Med. 1999, 340, 1605-1613. [CrossRef] [PubMed]

35. Hogg, R.S.; Rhone, S.A.; Yip, B.; Sherlock, C.; Conway, B.; Schechter, M.T.; O'Shaughnessy, M.V.; Montaner, J.S. Antiviral effect of double and triple drug combinations amongst HIV-infected adults: Lessons from the implementation of viral load-driven antiretroviral therapy. AIDS 1998, 12, 279-284. [CrossRef] [PubMed]

36. Richman, D.D.; Margolis, D.M.; Delaney, M.; Greene, W.C.; Hazuda, D.; Pomerantz, R.J. The challenge of finding a cure for HIV infection. Science 2009, 323, 1304-1307. [CrossRef] [PubMed]

37. Liu, S.; Lu, H.; Neurath, A.R.; Jiang, S. Combination of candidate microbicides cellulose acetate 1,2-benzenedicarboxylate and UC781 has synergistic and complementary effects against human immunodeficiency virus type 1 infection. Antimicrob. Agents Chemother. 2005, 49, 1830-1836. [CrossRef]

38. Pan, C.; Cai, L.; Lu, H.; Qi, Z.; Jiang, S. Combinations of the first and next generations of human immunodeficiency virus (HIV) fusion inhibitors exhibit a highly potent synergistic effect against enfuvirtidesensitive and -resistant HIV type 1 strains. J. Virol. 2009, 83, 7862-7872. [CrossRef]

39. Pan, C.; Lu, H.; Qi, Z.; Jiang, S. Synergistic efficacy of combination of enfuvirtide and sifuvirtide, the firstand next-generation HIV-fusion inhibitors. AIDS 2009, 23, 639-641. [CrossRef]

(C) 2019 by the authors. Licensee MDPI, Basel, Switzerland. This article is an open access article distributed under the terms and conditions of the Creative Commons Attribution (CC BY) license (http://creativecommons.org/licenses/by/4.0/). 